\title{
Synthesis of Norhalichondrin B
}

\section{Key words}

norhalichondrin B

Achmatowicz oxidation

Nozaki-HiyamaKishi reaction

asymmetric crotylation

ionic hydrogenation

chromium

SYNFACThath

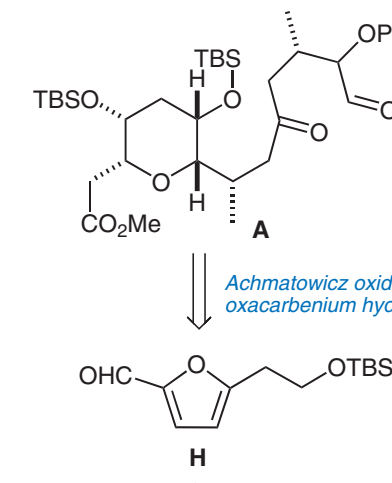

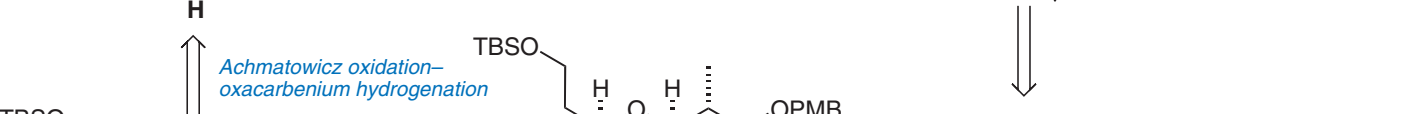

TBSO

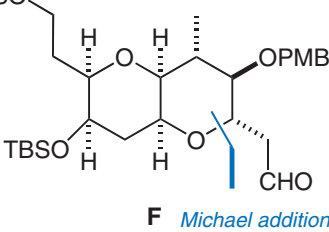

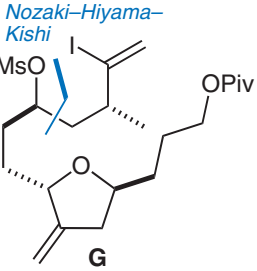

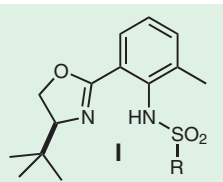

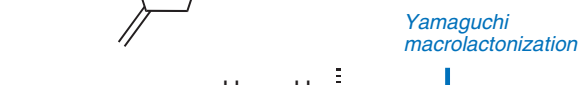

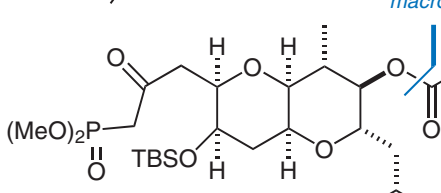

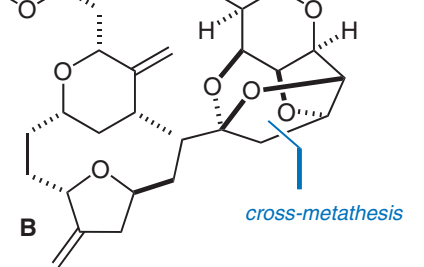

C

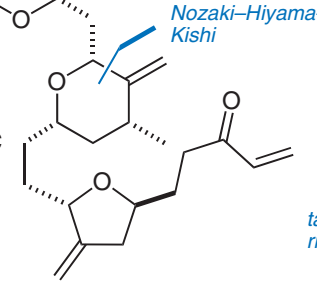

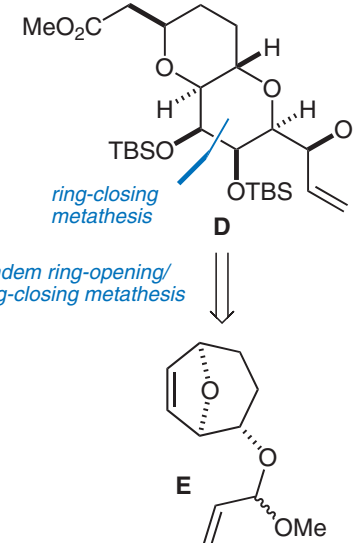

Significance: Norhalichondrin B is a marine polyether with potent cytotoxicity. Key to this synthetic approach are the Nozaki-Hiyama-Kishi reactions and the tandem Achmatowicz oxidation-ionic hydrogenation which form the pyranopyran systems.
Comment: The Nozaki-Hiyama-Kishi reactions were run in the presence of chiral ligand $\mathbf{I}$ where $\mathrm{R}$ was either methyl or naphthyl. The Achmatowicz oxidation-hydrogenation was highly diastereoselective $(d r>20: 1)$.

SYNFACTs Contributors: Philip Kocienski, Stewart Eccles 